Article

\title{
Screening Vitis Genotypes for Responses to Botrytis cinerea and Evaluation of Antioxidant Enzymes, Reactive Oxygen Species and Jasmonic Acid in Resistant and Susceptible Hosts
}

\author{
Mati Ur Rahman ${ }^{1,2,+}$, Muhammad Hanif ${ }^{1,2,+}$, Ran Wan ${ }^{1,3}$, Xiaoqing Hou ${ }^{1,2}$, Bilal Ahmad ${ }^{1,2}$ \\ and Xiping Wang $1,2, * \mathbb{D}$ \\ 1 State Key Laboratory of Crop Stress Biology in Arid Areas, College of Horticulture, \\ Northwest A\&F University, Yangling 712100, China; mati@nwafu.edu.cn (M.U.R.); \\ mhanif@nwafu.edu.cn (M.H.); wanran2012@nwsuaf.edu.cn (R.W.); houxiaoqing09@nwafu.edu.cn (X.H.); \\ bajwa1999@nwafu.edu.cn (B.A.) \\ 2 Key Laboratory of Horticultural Plant Biology and Germplasm Innovation in Northwest China, \\ Ministry of Agriculture, Northwest A\&F University, Yangling 712100, China \\ 3 College of Horticulture, Henan Agriculture University, Zhengzhou 450002, China \\ * Correspondence: wangxiping@nwsuaf.edu.cn; Tel.: +86-29-87082129 \\ + These authors contributed equally to this work.
}

Received: 28 October 2018; Accepted: 18 December 2018; Published: 20 December 2018

\begin{abstract}
Botrytis cinerea is a necrotrophic fungal phytopathogen with devastating effects on many Vitis genotypes. Here, a screening of 81 Vitis genotypes for leaf resistance to $B$. cinerea revealed two highly resistant (HR), twelve resistant (R), twenty-five susceptible (S) and forty-two highly susceptible (HS) genotypes. We focused on the HR genotype, 'Zi Qiu' (Vitis davidii), and the HS genotype 'Riesling' ( $V$. vinifera), to elucidate mechanisms of host resistance and susceptibility against $B$. cinerea, using detached leaf assays. These involved a comparison of fungal growth, reactive oxygen species (ROS) responses, jasmonic acid (JA) levels, and changes in the anti-oxidative system between the two genotypes after inoculation with B. cinerea. Our results indicated that the high-level resistance of 'Zi Qiu' can be attributed to insignificant fungal development, low ROS production, timely elevation of anti-oxidative functions, and high JA levels. Moreover, severe fungal infection of 'Riesling' and sustained ROS production coincided with relatively unchanged anti-oxidative activity, as well as low JA levels. This study provides insights into $B$. cinerea infection in grape, which can be valuable for breeders by providing information for selecting suitable germplasm with enhanced disease resistance.
\end{abstract}

Keywords: biotic stress; Botrytis cinerea; grape; resistant genotypes; reactive oxygen species; jasmonic acid; antioxidant enzymes

\section{Introduction}

Botrytis cinerea is a necrotrophic fungal phytopathogen that causes devastating gray mold disease in more than 200 dicotyledonous plant hosts, as well as some monocotyledonous species. This polyphagous pathogen is the second most prevalent phytopathogen responsible for pre-and postharvest decay and fruit quality deterioration in greenhouses, open fields, and during storage, including cold storage $\left(0-10^{\circ} \mathrm{C}\right)$ [1]. Grey mold is a major challenge to grape cultivation worldwide where periods of relative humidity $(>90 \%)$ and cold temperatures $\left(14-28^{\circ} \mathrm{C}\right)$ persist for a long time and coincide with bloom and ripening [2]. 
The traditional control of $B$. cinerea includes strong fungicide treatments during the seasonal crop cycle, and current strategies for control of Botrytis bunch rot rely on a combination of canopy management and fungicide usage. Physical methods, such as the use of fruit zone leaf removal, shoot positioning, and timely training and pruning can reduce disease severity, but these techniques are expensive, laborious, and less effective than fungicides [3,4]. In addition to increasing the cost of grape production, the use of chemical fungicides has an adverse impact on the environment, and potentially on consumer health [5]. There are also reports of fungal strains developing resistance to some commonly used fungicides and this has resulted in restrictions being adopted in the use of chemicals for crop protection [6-8]. Thus, the development of resistant, high-quality genotypes would reduce the dependence of the viticulture industry on pesticide input and have significant environmental and economic benefits. The most commonly cultivated species, V. vinifera, lacks resistance to many diseases, and the degree of susceptibility varies between cultivars and depends on environmental conditions $[9,10]$.

Previously, Wan et al., evaluated the responses of different wild Chinese Vitis genotypes to B. cinerea infection. However, the resistance level is highly variable among the clones of the same species, for example, Lueyang-4, Ningqiang-6 and Tangwei (Vitis davidii) [11]. In this study we investigated the responses of different Vitis genotypes i.e., eleven $(V$. vinifera $\times V$. labrusca), 65 ( $V$. vinifera), three $(V$. vinifera $\mathrm{L} \times V$. amurensis genotypes), one ( $V$. amurensis), and one clone of (Vitis davidii) to $B$. cinerea infection. The phenotypic and histochemical disease signs and symptoms at different levels of Vitis-B. cinerea interaction were evaluated in a total of 81 Vitis genotypes. In addition, we measured the levels of reactive oxygen species (ROS), which play important roles in plant physiology, including development, cellular signaling, and biotic and abiotic stress tolerance. ROS production needs to be tightly regulated to balance the physiological effects [12]. Substantial evidence indicates that $B$. cinerea challenge can overthrow the effects of ROS stress on plants $[13,14]$.

In addition to ROS, the plant hormone jasmonic acid (JA) is known to be involved in biotic stress amelioration [15]. For example, JA plays a key regulatory role in defense responses to necrotrophs [16] and in participating in responses to injury and biotic stresses, such as occur during insect and pathogen attacks [17]. In this study, we investigated the levels of ROS, the antioxidant enzymes, and JA in the leaves of highly resistant (HR) and highly susceptible (HS) Vitis genotypes. These results were correlated with disease resistance at different time points post-inoculation with $B$. cinerea, generating information that may assist in future breeding programs.

\section{Results}

\subsection{Grape Genotypes Exhibit Different Levels of Resistance to B. cinerea}

Detached leaf assays were used to evaluate $B$. cinerea infection in vitro [18] and the spread of leaf lesions caused by B. cinerea were measured at 96 hpi (hours post inoculation) (Figure 1). Some genotypes displayed significant differences in B. cinerea resistance (Table 1), and a completely randomized least significant difference (LSD) analysis showed that the similarity was found among the replicates, and that the average disease severity was significantly different $(p \leq 0.05)$ between the various genotypes (Table 1). No significant difference $(p>0.05)$ was found between the 2016 and 2017 data (Table S2). 


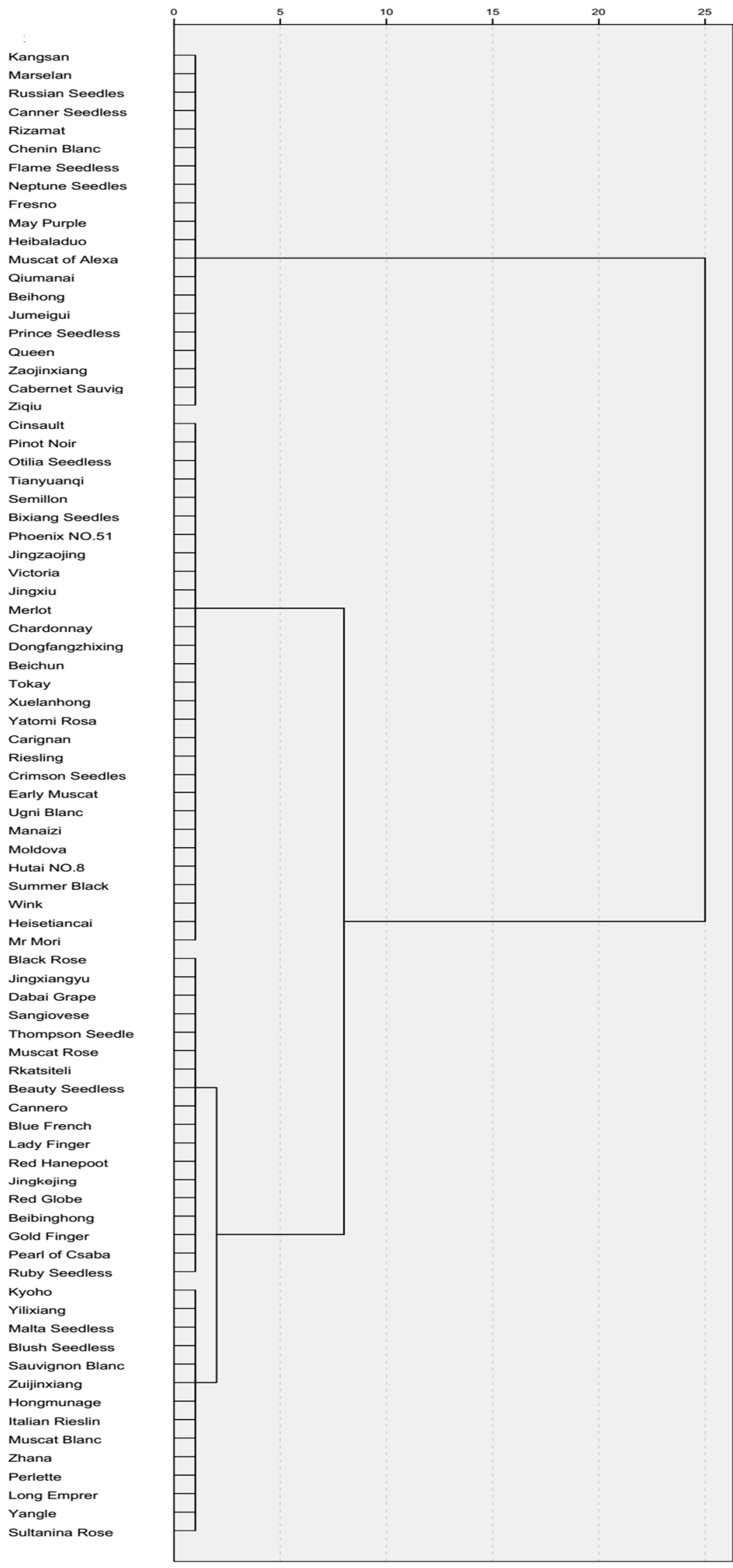

Figure 1. Clustering of various Vitis genotypes based on leaf lesion percentage, $96 \mathrm{~h}$ post inoculation with Botrytis cinerea. 
Table 1. Laboratory evaluation of disease severity in 81 Vitis genotypes, following inoculation with Botrytis cinerea in 2016 and 2017.

\begin{tabular}{|c|c|c|c|c|}
\hline Species & $\begin{array}{l}\text { Name of } \\
\text { Genotype }\end{array}$ & $\begin{array}{c}\text { Disease } \\
\left.\text { Severity }{ }^{\text {a }} \%\right)\end{array}$ & Resistance Level ${ }^{\text {b }}$ & Geographical Origin \\
\hline V. vinifera $\mathrm{L}$. & Beauty Seedless & 83.6 & HS & University of California, Davis, CA, USA \\
\hline $\begin{array}{l}\text { V. vinifera } \mathrm{L} . \times V \text {. } \\
\text { amurensis Rupr }\end{array}$ & Beibinghong & 84.6 & HS & $\begin{array}{l}\text { 1995, Institute of Special Animal and Plant Science } \\
\text { of CAAS, Beijing, China }\end{array}$ \\
\hline $\begin{array}{l}V . \text { vinifera } \mathrm{L} . \times V \text {. } \\
\text { amurensis Rupr }\end{array}$ & Beichun & 93.6 & HS & $\begin{array}{l}\text { 1954, Beijing Botanical Garden Institute of Botany, } \\
\text { Chinese Academy of Science, Beijing, China }\end{array}$ \\
\hline $\begin{array}{l}\text { V. vinifera L. } \times V \text {. } \\
\text { amurensis Rupr }\end{array}$ & Beihong & 42.4 & $\mathrm{~s}$ & $\begin{array}{l}\text { 1954, Beijing Botanical Garden Institute of Botany, } \\
\text { Chinese Academy of Science, China }\end{array}$ \\
\hline$V$ vinifera $\mathrm{L}$. & Bixiang Seedless & 92.2 & HS & $\begin{array}{l}\text { 1994, Jilin Academy of Agricultural Science, } \\
\text { Changchun, China }\end{array}$ \\
\hline$V$. vinifera $\mathrm{L}$. & Black Rose & 76.5 & $\mathrm{~S}$ & $\begin{array}{l}\text { The Division of Horticultural Research of } \\
\text { Commonwealth Scientific and Industrial Research } \\
\text { Organization (CSIRO), Melbourne, Australia }\end{array}$ \\
\hline V. vinifera $\mathrm{L}$. & Blue French & 76.5 & $\mathrm{~S}$ & Austria \\
\hline V. vinifera $\mathrm{L}$. & Blush Seedless & 71.8 & $\mathrm{~S}$ & Professor Olmo, Davis Station, CA, USA. \\
\hline$V$. vinifera $\mathrm{L}$. & $\begin{array}{l}\text { Cabernet } \\
\text { Sauvignon }\end{array}$ & 22.7 & $\mathrm{R}$ & Aquitaine, Bordeaux, France \\
\hline V. vinifera $\mathrm{L}$. & Canner Seedless & 40.5 & $\mathrm{~S}$ & University of California, Davis, CA, USA. \\
\hline V. vinifera $\mathrm{L}$. & Cannero & 80.5 & HS & Cannero Riviera, Italy \\
\hline V. vinifera $\mathrm{L}$. & Carignan & 93.7 & HS & Carinena, Aragon, Spain \\
\hline V. vinifera $\mathrm{L}$. & Chardonnay & 96.1 & HS & Burgundy, France \\
\hline V. vinifera $\mathrm{L}$. & Chenin Blanc & 27.4 & $\mathrm{R}$ & Anjou, Loire Valley, France \\
\hline V. vinifera $\mathrm{L}$. & Cinsault & 91.2 & HS & Languedoc, France \\
\hline V. vinifera $\mathrm{L}$. & Crimson Seedless & 94.2 & HS & $\begin{array}{c}\text { Institute of Fruit Tree Research of Changli, Hebei } \\
\text { Academy of Agriculture and Forestry Science, } \\
\text { Shijiazhuang, China }\end{array}$ \\
\hline V. vinifera $\mathrm{L}$. & Dabai Grape & 73.2 & $\mathrm{~S}$ & Unknown \\
\hline $\begin{array}{l}\text { V. vinifera L. } \times \\
\text { V. labrusca L. }\end{array}$ & Dong fang zhixing & 94.3 & HS & 2007, Hiroshima, Japan \\
\hline V. vinifera $\mathrm{L}$. & Early Muscat & 98.6 & HS & 1997, Shandong Province, Jinan, China \\
\hline V. vinifera $\mathrm{L}$. & Flame Seedless & 45.8 & S & 1973, Freson, CA, USA \\
\hline V. vinifera $\mathrm{L}$. & Fresno Seedless & 51.7 & $\mathrm{~s}$ & Fresno, CA, USA \\
\hline $\begin{array}{l}\text { V. vinifera } \mathrm{L} . \times \\
\text { V. labrusca } \mathrm{L} \text {. }\end{array}$ & Gold Finger & 83.6 & HS & 1982, Japan \\
\hline $\begin{array}{l}\text { V. vinifera } \mathrm{L} . \times \\
\text { V. labrusca } \mathrm{L} \text {. }\end{array}$ & Hei bala duo & 39.2 & $\mathrm{R}$ & 2004, Kumamoto Prefecture, Japan \\
\hline V. vinifera $\mathrm{L}$. & Heise tiancai & 93.0 & HS & 2009, Kofu, Japan \\
\hline V. vinifera $\mathrm{L}$. & Hongmu nage & 58.7 & $\mathrm{~S}$ & Atux, Xinjiang, China \\
\hline $\begin{array}{l}\text { V. vinifera } \mathrm{L} . \times \\
\text { V. labrusca } \mathrm{L} .\end{array}$ & Hutai NO.8 & 93.6 & HS & Grape Institute, Xian, China \\
\hline V. vinifera $\mathrm{L}$. & Italian Riesling & 59.9 & $\mathrm{~S}$ & Italy \\
\hline V. vinifera $\mathrm{L}$. & Jing xiu & 92.0 & HS & 1994, Chinese Academy of Science, Beijing, China \\
\hline V. vinifera $\mathrm{L}$. & Jing ke jing & 81.2 & HS & 1984, Chinese Academy of Science, Beijing, China \\
\hline V. vinifera $\mathrm{L}$. & Jingzaojing & 91.8 & HS & 1984, Chinese Academy of Science, Beijing, China \\
\hline V. vinifera $\mathrm{L}$. & Jinxiangyu & 78.5 & HS & 1997, Chinese Academy of Science, Beijing, China \\
\hline$V$ vinifera $\mathrm{L}$. & Ju mei gui & 4.6 & HR & $\begin{array}{c}\text { Dalian Academy of Agriculture Science, Dalian, } \\
\text { China }\end{array}$ \\
\hline $\begin{array}{l}\text { V. riparia L. } \times \\
\text { V. labrusca L. }\end{array}$ & Kang san & 18.0 & $\mathrm{R}$ & Unknown \\
\hline $\begin{array}{l}\text { V. vinifera } \mathrm{L} . \times \\
\text { V. labrusca } \mathrm{L} \text {. }\end{array}$ & Kyoho & 25.7 & $\mathrm{R}$ & 1937, Japan \\
\hline V. vinifera $\mathrm{L}$. & Lady Finger & 87.6 & HS & 1984, Japan \\
\hline V. vinifera $\mathrm{L}$. & Long Emprer & 48.8 & $\mathrm{~S}$ & Unknown \\
\hline V. vinifera $\mathrm{L}$. & Malta Seedless & 73.6 & $\mathrm{~S}$ & Malta \\
\hline V. vinifera $\mathrm{L}$. & Manaizi & 95.2 & HS & Tulufan, Xinjiang, China \\
\hline
\end{tabular}


Table 1. Cont.

\begin{tabular}{|c|c|c|c|c|}
\hline Species & $\begin{array}{l}\text { Name of } \\
\text { Genotype }\end{array}$ & $\begin{array}{c}\text { Disease } \\
\text { Severity }{ }^{\text {a }}(\%)\end{array}$ & Resistance Level $^{b}$ & Geographical Origin \\
\hline$V$ vinifera $\mathrm{L}$. & Marselan & 24.6 & $\mathrm{R}$ & France \\
\hline V. vinifera $\mathrm{L}$. & May Purple & 38.0 & $\mathrm{R}$ & Unknown \\
\hline$V$. vinifera $\mathrm{L}$. & Merlot & 94.5 & HS & Bordeaux, France \\
\hline$V$. vinifera $\mathrm{L}$. & Moldova & 95.3 & HS & Moldova \\
\hline$V$. vinifera $\mathrm{L}$. & Mr Mori & 94.5 & HS & 1985, Japan \\
\hline V. vinifera $\mathrm{L}$. & Muscat Blanc & 63.4 & S & Eastern Mediterranean \\
\hline V. vinifera $L$ & $\begin{array}{l}\text { Muscat of } \\
\text { Alexandia }\end{array}$ & 42.0 & $S$ & Egypt \\
\hline$V$. vinifera $\mathrm{L}$. & Muscat Rose & 78.1 & HS & Greece \\
\hline $\begin{array}{l}\text { V. vinifera } \mathrm{L} . \times \\
\text { V. labrusca } \mathrm{L} .\end{array}$ & Neptune Seedless & 47.2 & $\mathrm{~S}$ & 1998, University of Arkansas, AR, USA. \\
\hline$V$. vinifera $\mathrm{L}$. & Otilia Seedless & 93.2 & HS & Romania \\
\hline V. vinifera $\mathrm{L}$. & Pearl of Csaba & 85.3 & HS & 1904, Hungary. \\
\hline V. vinifera $\mathrm{L}$. & Perlette & 59.5 & $S$ & Fresno, CA, USA. \\
\hline V. vinifera $\mathrm{L}$. & Phoenix NO.51 & 88.5 & HS & Germany \\
\hline$V$ vinifera $\mathrm{L}$. & Pinot Noir & 94.0 & HS & Burgundy, France \\
\hline$V$. vinifera $\mathrm{L}$. & Prince Seedless & 23.4 & $\mathrm{R}$ & $\begin{array}{l}\text { Hebei academy of agriculture and forestry science, } \\
\text { Changli, China }\end{array}$ \\
\hline V. vinifera $\mathrm{L}$. & Qiu manai & 41.6 & S & Atushi, Xinjiang, China \\
\hline V. vinifera $\mathrm{L}$. & Queen & 24.6 & $\mathrm{R}$ & Unknown \\
\hline$V$ vinifera $\mathrm{L}$. & Red Globe & 85.0 & HS & University of California, CA, USA \\
\hline V. vinifera $\mathrm{L}$. & Red Hanepoot & 82.1 & HS & Unknown \\
\hline V. vinifera $\mathrm{L}$. & Riesling & 98.0 & HS & Germany \\
\hline V. vinifera $\mathrm{L}$. & Rizamat & 27.3 & $\mathrm{R}$ & The Soviet Union \\
\hline V. vinifera $\mathrm{L}$. & Rkatsiteli & 75.0 & S & Georgia \\
\hline V. vinifera $\mathrm{L}$. & Ruby Seedless & 86.3 & HS & University of California, CA, USA. \\
\hline V. vinifera $\mathrm{L}$. & Russian Seedless & 27.2 & $\mathrm{R}$ & Australia \\
\hline V. vinifera $\mathrm{L}$. & Sangiovese & 78.1 & HS & Italy \\
\hline$V$ vinifera $\mathrm{L}$. & Sauvignon Blanc & 71.4 & $\mathrm{~S}$ & France \\
\hline V. vinifera $\mathrm{L}$. & Semillon & 93.2 & HS & France \\
\hline V. vinifera $L$ & Sultanina Rose & 54.6 & S & Unknown \\
\hline $\begin{array}{l}\text { V. vinifera } \mathrm{L} . \times \\
\text { V. labrusca } \mathrm{L} .\end{array}$ & Summer Black & 97.6 & HS & 1968, Yamanashi Prefecture, Japan \\
\hline$V$. vinifera $\mathrm{L}$. & $\begin{array}{l}\text { Thompson } \\
\text { Seedless }\end{array}$ & 76.2 & S & Tulufan, Xinjiang, China \\
\hline $\begin{array}{l}\text { V. vinifera } \mathrm{L} . \times \\
\text { V. labrusca } \mathrm{L} .\end{array}$ & Tian yuan qi & 90.0 & HS & 1994, Fruit Insitute, Liaoning, China \\
\hline V. vinifera $\mathrm{L}$. & Tokay & 93.9 & HS & Hungary \\
\hline V. vinifera $\mathrm{L}$. & Ugni Blanc & 97.6 & HS & Italy \\
\hline V. vinifera $\mathrm{L}$. & Victoria & 92.0 & HS & Romania \\
\hline V. vinifera $\mathrm{L}$. & Wink & 93.4 & HS & 1998, Japan \\
\hline V. amurensis Rupr & Xue lanhong & 94.4 & HS & $\begin{array}{l}\text { Institute of Special Animal and Plant Science of } \\
\text { CAAS, Jilin, China }\end{array}$ \\
\hline$V$. vinifera $\mathrm{L}$. & Yangle & 55.8 & $S$ & Russia \\
\hline V. vinifera $\mathrm{L}$. & Yatomi Rosa & 95.2 & HS & 1990, Japan \\
\hline V. vinifera $\mathrm{L}$. & Yili xiang & 69.8 & S & Yili, Xinjiang, China \\
\hline $\begin{array}{l}\text { V. vinifera } \mathrm{L} . \times \\
\text { V. labrusca } \mathrm{L} .\end{array}$ & Zao jin xiang & 28.2 & $\mathrm{R}$ & 1963, Grape institute, Liaoning, China \\
\hline V. vinifera $\mathrm{L}$. & Zhana & 63.8 & S & Albania \\
\hline V. davidii Foex & Zi qiu & 3.3 & HR & 2004, Hunan Agricultural University, Hunan, China \\
\hline $\begin{array}{l}\text { V. vinifera } \mathrm{L} . \times \\
\text { V. labrusca } \mathrm{L} .\end{array}$ & Zui jin xiang & 67.8 & S & $\begin{array}{c}\text { 1997, Liaoning Academy of Agriculture Science, } \\
\text { China }\end{array}$ \\
\hline
\end{tabular}

${ }^{a}$ Disease severity: the average percentage of spreading lesions determined by observation of at least 24 leaves in each 2016 and 2017 experiment. ${ }^{b}$ Resistance level: Highly Resistant (HR: rank of 0-1.50); Resistant (R: rank of 1.51-3.50); Susceptible (S: rank of 3.51-5.50); Highly Susceptible (HS: rank of 5.51-7.0). 
In total, 81 Vitis genotypes were evaluated to investigate the resistance level against B. cinerea. All genotypes were classified according to their disease severity index (SI) at $96 \mathrm{~h}$ post-inoculation (hpi). Among the 81 genotypes, 42 (Table 1) were HS according to a disease SI of 5.51-7.0. Mycelium and sporulation was observed on these genotypes. A total of 25 genotypes (Table 1) were $S$, with mycelium production at $96 \mathrm{hpi}$, with no/less sporulation (SI of 3.51-5.50). A total of 12 genotypes (Table 1) were resistant, with much less mycelium production and no sporulation was observed in genotypes with SI values of 1.51-3.50. The 'Zi Qiu' and 'Ju Mei Gui' genotypes (Table 1) were HR with no mycelium or sporulation and with SI values of $0-1.50$.

Two representative genotypes each from the HS, S, R and HR categories were chosen for macroscopic and microscopic evaluation of fungal growth at 96 hpi (Figure 2). The leaves of the HS 'Riesling' (Figure 2D,L) and 'Pinot noir' (Figure 2H,P) genotypes were completely covered in mold and were roofed by mycelium, as well as showing signs of sporulation. The $S$ genotypes 'Flame' (Figure 2C,K) and 'Canner' (Figure 2G,O) had numerous mycelia but showed no signs of sporulation. The R genotypes 'Kang San' (Figure 2B,J) and 'Rizamat' (Figure 2F,N) formed significantly fewer necrotic lesions than the HS and S genotypes. Moreover, conidia with penetrating pegs were observed on the leaves of 'Kang San' and 'Rizamat'; however, the resulting hyphae did not extend, indicating restricted B. cinerea proliferation. The HR genotypes 'Zi Qiu' (Figure 2A,I) and 'Ju Mei Gui' (Figure $2 \mathrm{E}, \mathrm{M}$ ) had $2 \%$ and $8 \%$ lesion areas, respectively (Table S1).

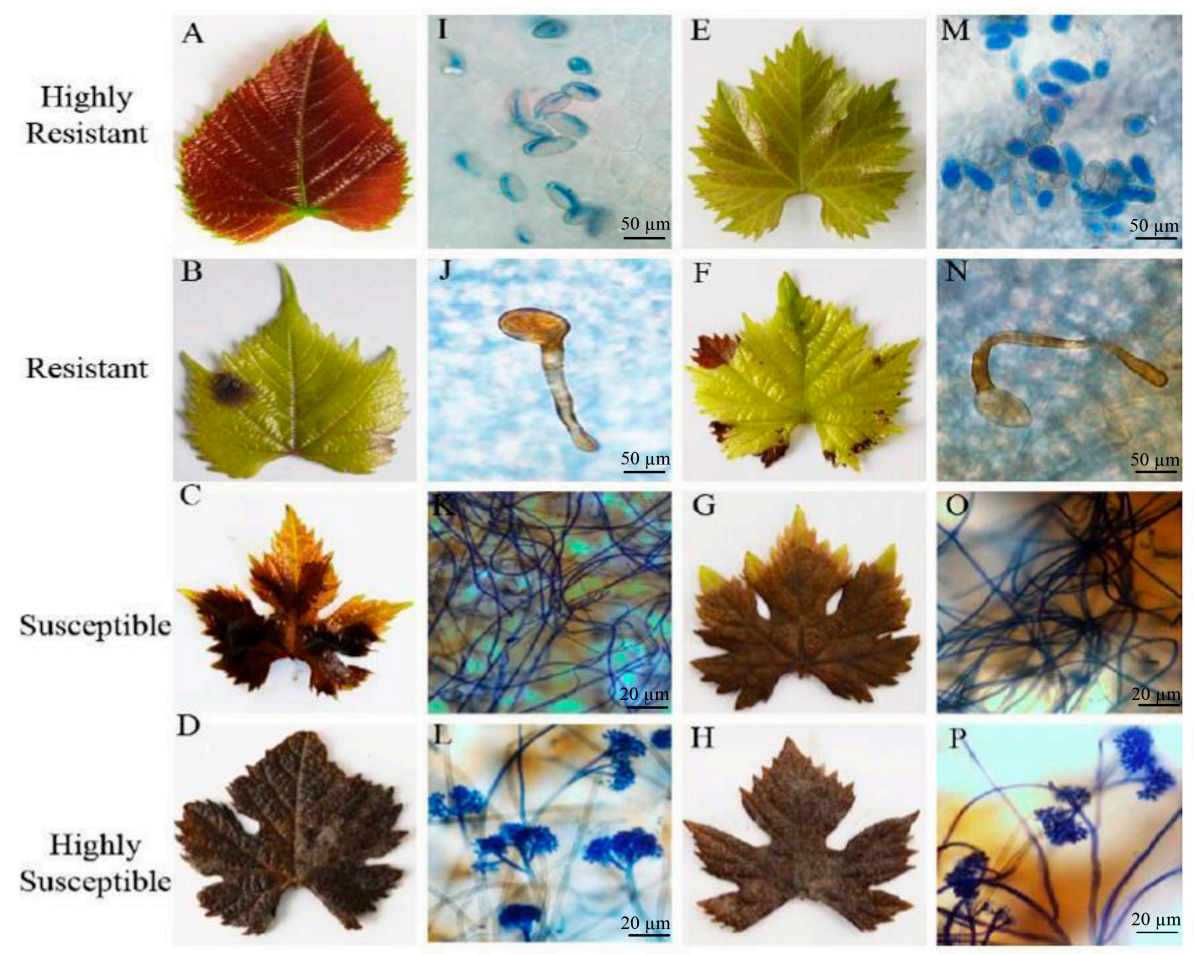

Figure 2. Macroscopic (A-D and $\mathbf{E}-\mathbf{H}$ ) and microscopic (I-L and $\mathbf{M}-\mathbf{P}$ ) evaluation of two representative Vitis genotypes, collectively representing the different Botrytis cinerea resistance levels. Highly resistant genotypes 'Zi Qiu' and 'Ju Mei Gui' are shown in (A,I) and (E,M), respectively. Resistant genotypes 'Kang San' and 'Rizamat' are shown in $(\mathbf{B}, \mathbf{J})$ and $(\mathbf{F}, \mathbf{N})$, respectively. 'Flame' and 'Canner' represent susceptible genotypes and are shown in $(\mathbf{C}, \mathbf{K})$ and $(\mathbf{G}, \mathbf{O})$, respectively. 'Riesling' and 'Pinot noir' are highly susceptible and are shown in $(\mathbf{D}, \mathbf{L})$ and $(\mathbf{H}, \mathbf{P})$, respectively. Scale bars $(\mathbf{I}, \mathbf{J}, \mathbf{M}, \mathbf{N}): 50 \mu \mathrm{m}$; $(\mathbf{K}, \mathbf{L}, \mathbf{O}, \mathbf{P}): 20 \mu \mathrm{m}$. Samples were collected $96 \mathrm{~h}$ after inoculation and then one representative leaf of three biological replicates were analyzed. 


\subsection{B. cinerea Growth on the HR Genotype 'Zi Qiu' and the HS Genotype 'Riesling'}

To understand the development of $B$. cinerea on grape leaves from plants showing different resistance levels, we analyzed the two grape genotypes, 'Zi Qiu' (HR, V. davidii) and 'Riesling' (HS, $V$. vinifera), using scanning electron microscopy (SEM). At $4 \mathrm{hpi}$, their phenotypes were approximately the same (Figure 3A,J). At 24 hpi, spore germination was clearly delayed, and fungal growth was mostly blocked on 'Zi Qiu' leaves (Figure 3A-I). The infection rate on 'Riesling' leaves was more significant and destructive than that of 'Zi Qiu' (Figure 3J-R), which B. cinerea failed to infect. The presence of appressoria was first noted at $18 \mathrm{hpi}$ (Figure 3D) on 'Zi Qiu', after which time the progression of infection increased slowly until 48 hpi (Figure 3D,G). At 8 hpi, appressoria were present on 'Riesling' (Figure 3K), while penetrations became apparent at $12 \mathrm{hpi}$ (Figure 3L). The infection rate increased at $18 \mathrm{hpi}$, where infection pegs were clearly seen (Figure 3M) and again at 24 hpi, (Figure 3N), and infection hypha and necrotic spots appeared after 36 hpi (Figure 3O). From 24 hpi, fungal growth was blocked on 'Zi Qiu', and the infection was abolished (Figure 3E). Hollow conidia, as well as some appresoria (Figure 3F), were present at 18 hpi until 96 hpi (Figure 3H,I). In contrast, fungal germination and infection was noted at $24 \mathrm{hpi}$ on susceptible 'Riesling' leaves, which progressively increased until 96 hpi (Figure 3R). Some hyphae were branched (Figure 3Q) with apparent lesions forming. From 48 hpi onward, the fungus spread and showed sporulation on 'Riesling' (Figure 3P).

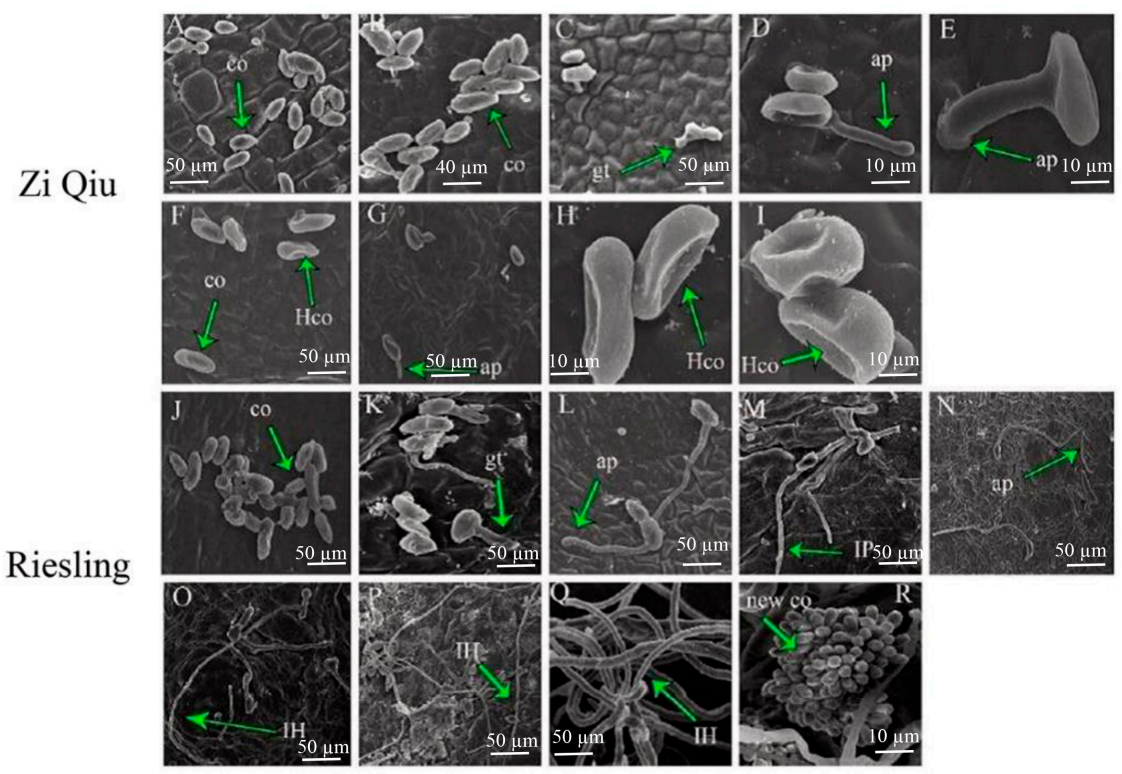

Figure 3. Comparison of Botrytis cinerea conidia development on 'Zi Qiu' and 'Riesling' leaves using scanning electron microscopy. Progression of B. cinerea colonization on 'Zi Qiu' (A-I) and 'Riesling' (J-R). Leaves were harvested at 4, 8, 12, 18, 24, 36, 48, 72, and $96 \mathrm{hpi}$, and the experiments were repeated three times. Arrows indicate co, conidia; gt, germ tube; ap, appressoria; IP, infection peg; IH, infection hypha; new co, new conidia; and Hco, hollow conidia.

2.3. Activity of Peroxidase and Superoxide Dismutase in the HR Genotype 'Zi Qiu' and the HS Genotype 'Riesling' Infected by B. cinerea

We measured the activities of superoxide dismutase (SOD) and peroxidase (POD) in the infected and control leaves. Stress conditions disrupt ROS production leading to plant cell death but plants exhibit an array of anti-oxidant enzymes to scavenge harmful ROS and protect cells from oxidative damage [19]. SOD activities in the 'Zi Qiu' (V. davidii) and 'Riesling' (V. vinifera) control samples were approximately the same, except for a slightly elevated level at 4 hpi (Figure 4A) in 'Riesling'. The activity in the inoculated ' $\mathrm{Zi}$ Qiu' was approximately twice that of the control throughout the experiment (Figure 4A). The SOD activity in 'Riesling' was similar to that in 'Zi Qiu' at 4 hpi (Figure 4A), but then increased from 4 hpi to 18 hpi, where it peaked before decreasing again until 96 hpi. 

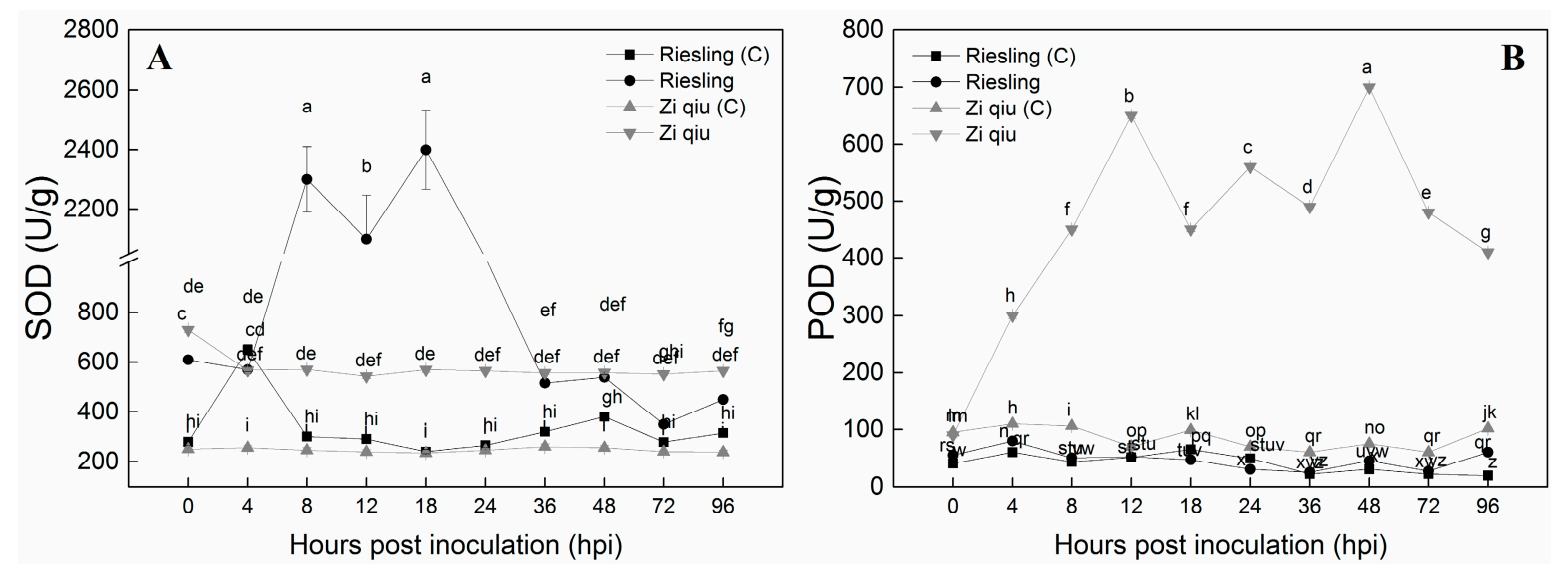

Figure 4. Superoxide dismutase (SOD) (A) and peroxidase (POD) (B) activities of protein extracts from 'Zi Qiu' and 'Riesling' leaves at 0, 4, 8, 12, 18, 24, 36, 48, 72, and $96 \mathrm{~h}$ post-inoculation (hpi) with Botrytis cinerea, using sterile water as the control. Three independent experiments were used for the means and standard errors. Small alphabetes indicate significant differences according to LSD test $(p<0.05)$ between "Zi qiu" and "Riesling".

POD activities in HR 'Zi Qiu' (V. davidii) and HS 'Riesling' (V. vinifera) leaves were determined to evaluate the robustness of the antioxidant system during $B$. cinerea infection. The control samples of both genotypes, as well as inoculated 'Riesling', had approximately the same POD background activities over the entire time course (Figure 4B). However, in inoculated 'Zi Qiu' leaves, POD activity increased from $4 \mathrm{hpi}$ to a maximum of $48 \mathrm{hpi}$, and then decreased until $96 \mathrm{hpi}$ (Figure 4B).

\subsection{Hydrogen Peroxide $\left(\mathrm{H}_{2} \mathrm{O}_{2}\right)$ Accumulation in HR 'Zi Qiu' and HS 'Riesling' Leaves in Response to Infection with $B$. cinerea}

Figure 5 shows $\mathrm{H}_{2} \mathrm{O}_{2}$ levels in leaves of 'Zi Qiu' ( $V$. davidii) and 'Riesling' (V. vinifera) after inoculation with $B$. cinerea. The maximum $\mathrm{H}_{2} \mathrm{O}_{2}$ content (Figure $5 \mathrm{~A}$ ) was observed in 'Riesling', while the minimum $\mathrm{H}_{2} \mathrm{O}_{2}$ (Figure 5A) level was observed in ' $\mathrm{Zi}$ Qiu' at various time points $(0,4,8,12,18$, 24, 36, 48, 72, and $96 \mathrm{hpi}$. Under stress conditions, at $0 \mathrm{hpi}, \mathrm{H}_{2} \mathrm{O}_{2}$ levels were similar in ' $\mathrm{Zi} \mathrm{Qiu'} \mathrm{and}$ 'Riesling' (Figure 5A). $\mathrm{H}_{2} \mathrm{O}_{2}$ production increased gradually in 'Riesling' from $4 \mathrm{hpi}$ to $96 \mathrm{hpi}$, except for slight downward trend at 18 and 36 hpi. No significant increase was observed in 'Zi Qiu'compared to 'Riesiling' at any time point (Figure 5A) and there was no significant increase in reponse to the control treatments in either genotype.
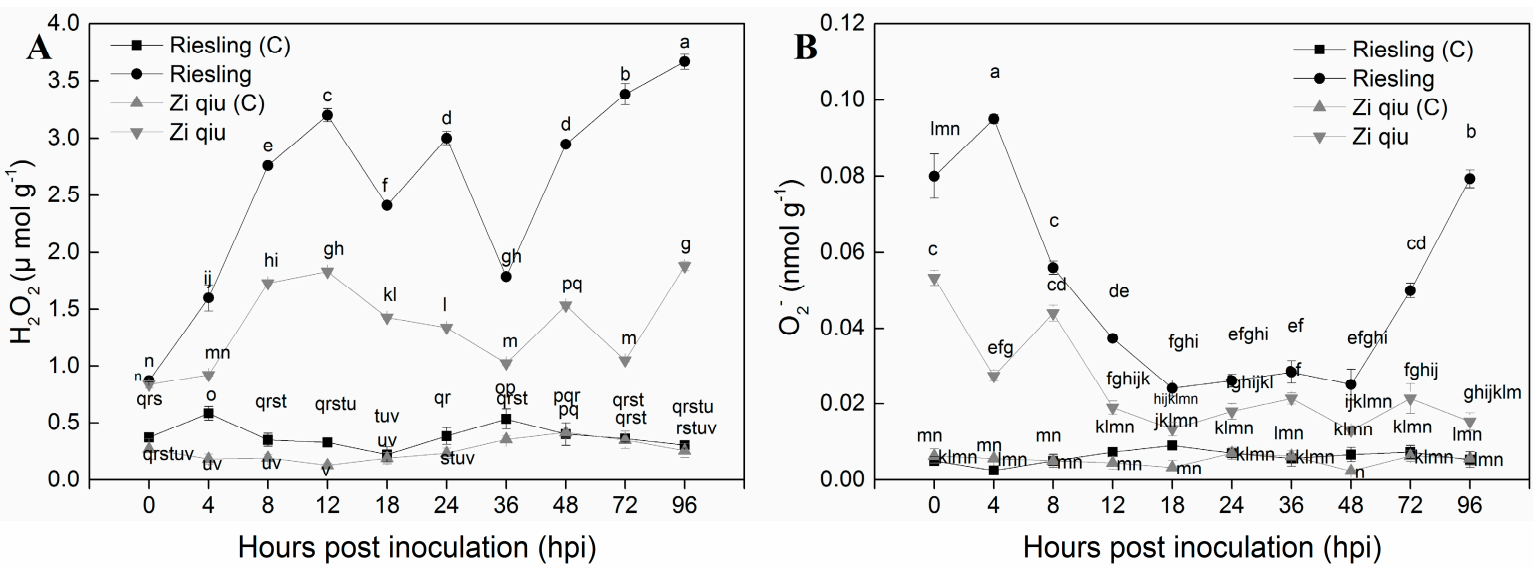

Figure 5. Levels of $\mathrm{H}_{2} \mathrm{O}_{2}$ (A) and $\mathrm{O}_{2}{ }^{-}$(B) in leaves of highly resistant 'Zi Qiu' and highly susceptible 'Riesling' at $0,4,8,12,18,24,36,48,72$, and 96 hpi with Botrytis cinerea and using sterile water as the control. Three independent experiments were used for the means and standard errors. Small alphabetes indicate significant differences according to LSD test $(p<0.05)$ between "Zi qiu" and "Riesling". 
2.5. Accumulation of Superoxide Radicals $\left(\mathrm{O}_{2}{ }^{-}\right)$in $H R$ ' Zi Qiu' and HS 'Riesling' Leaves in Response to Infection with B. cinerea

Higher $\mathrm{O}_{2}{ }^{-}$(Figure 5B) levels were observed in 'Riesling' (V. vinifera) than in 'Zi Qiu' (V. davidii) at most time points. $\mathrm{O}_{2}{ }^{-}$production from 0 to 4 hpi showed opposite trends in 'Zi Qiu' and 'Riesling' (Figure 5B). From 8-48 hpi the levels were stable in both genotype; however, a significant increase from 48 to 96 hpi was detected in 'Riesling'. No significant change was observed in the controls of either genotype.

\subsection{Jasmonic Acid Levels in Leaves of the HR Genotype 'Zi Qiu' and the HS Genotype 'Riesling' Following} Inoculation with B. cinerea

JA levels were determined in both 'Zi Qiu' (V. davidii) and 'Riesling' (V. davidii) samples isolated from inoculated and control treatments at various time points. JA levels were higher in 'Zi Qiu' (Figure 6) than in 'Riesling' (Figure 6) at all time points. JA levels in the 'Zi Qiu' control were the same as for 'Riesling' inoculated from 0 to $96 \mathrm{hpi}$.

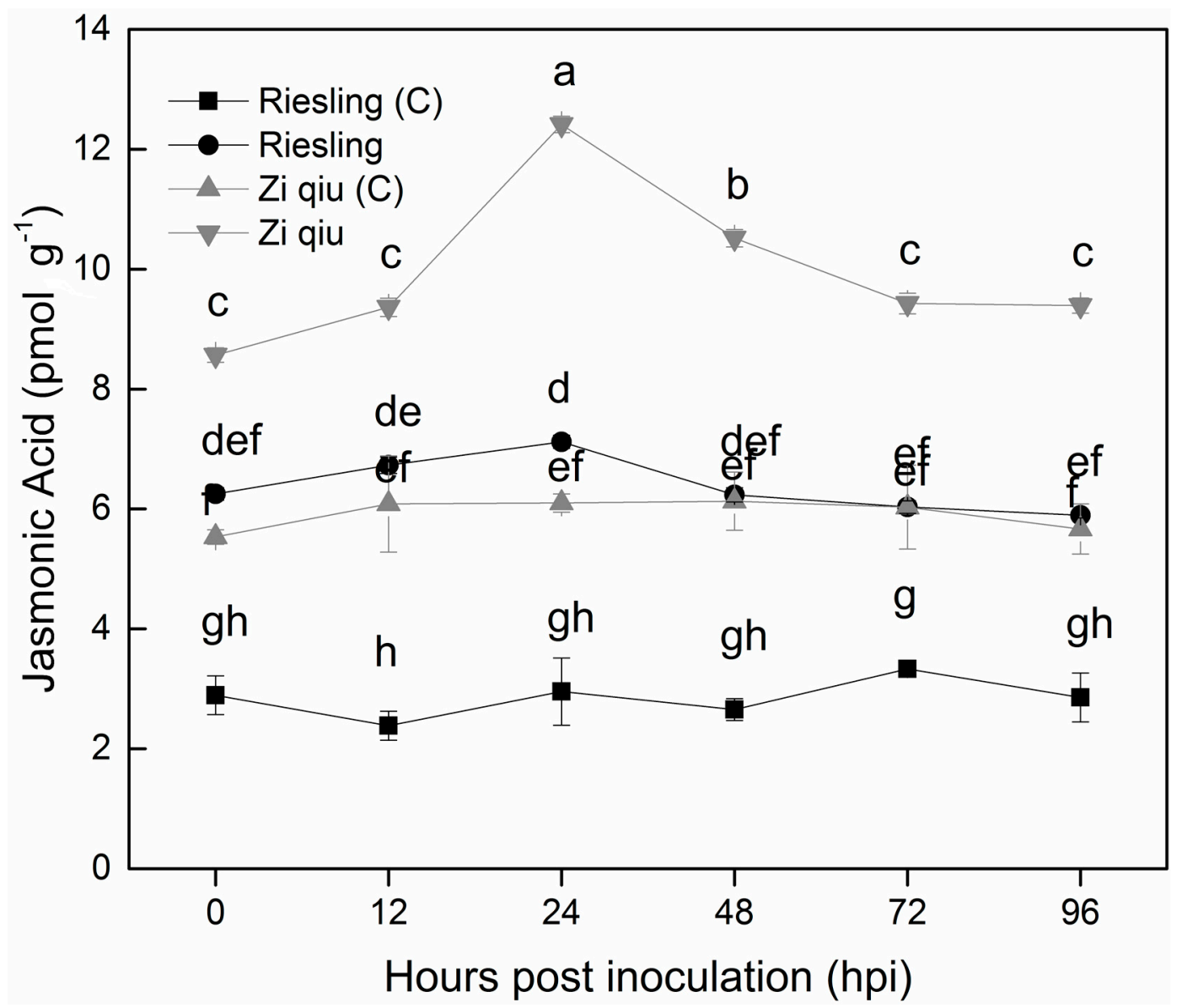

Figure 6. Jasmonic acid (JA) levels in highly resistant 'Zi Qiu' and highly susceptible 'Riesling' leaves at $0,12,24,48,72$, and 96 hpi with Botrytis cinerea and using sterile water as the control. Three independent experiments were used for the means and standard errors. Small alphabetes indicate significant differences according to LSD test $(p<0.05)$ between "Zi qiu" and "Riesling".

\subsection{Pearson's Correlation Coefficients}

Table 2 shows the Pearson's correlation coefficient values of the antioxidant enzyme activities, ROS levels and JA levels in 'Zi Qiu 'and 'Riesling' leaves. Significant positive correlations for SOD and POD activities with $\mathrm{H}_{2} \mathrm{O}_{2}$ and $\mathrm{O}_{2}{ }^{-}$levels were observed. SOD activity was significantly negatively correlated with JA levels, but positively correlated with POD activity. 
Table 2. Pearson's correlation coefficients of antioxidant enzyme activities, with reactive oxygen species (ROS) and jasmonic acid (JA) contents in 'Zi Qiu' and 'Riesling' leaves.

\begin{tabular}{cccc}
\hline & JA & $\mathbf{O}_{2}{ }^{-}$ & $\mathbf{H}_{2} \mathbf{O}_{2}$ \\
\hline SOD & $-0.9959 *$ & $0.8182{ }^{*}$ & $0.8974 *$ \\
\hline POD & 0.0831 & $0.5278 *$ & $0.3975 *$ \\
\hline
\end{tabular}

SOD, superoxide dismutase; POD, peroxidase; $\mathrm{H}_{2} \mathrm{O}_{2}$, hydrogen peroxide; $\mathrm{O}_{2}{ }^{-}$, superoxide radicals; JA, jasmonic acid. * Significant at the 0.01 probability level.

\section{Discussion}

Grape genotypes vary in terms of their infection resistance, degree of fungal colonization, and disease severity to B. cinerea [20]. Of the 81 different Vitis genotypes evaluated here, two were categorized as HR, twelve as resistant, twenty-five as S, and forty-two as HS (Table 1). Resistant genotypes towards B. cinerea have been found in Vitis species for example, V. davidii, V. vinifera and in the progeny of crosses between $V$. vinifera and species like $V$. labrusca (Table 1). Numerous wild Chinese Vitis species show multi-fungal disease resistance [21], and they have been described as important resources for future disease resistance breeding programs [22,23].

Discrete colonization of $B$. cinerea on grape leaves was studied by SEM at different time points. In 'Riesling', the pathogen initially showed limited infection, as indicated by necrosis prior to $24 \mathrm{hpi}$, but then spread substantially, and showed signs of sporulation. Prior to $24 \mathrm{hpi}$, fungal growth in ' $\mathrm{Zi}$ Qiu' leaves was significantly delayed, as evidenced by the lower germination and infection rates. Most B. cinerea appressoria on the 'Zi Qiu' leaves did not develop into infection pegs, in contrast to those on 'Riesling' leaves, and consistent with previous reports [11]. It was also reported that sporulation densities on $V$. davidii var. Langao-5 and $V$. pseudoreticulata var. Baihe-35-1 was significantly lower than those on the HS cultivar $V$. vinifera cv. Pinot noir [24]. Here, we saw that at the initial stages B. cinerea colonization halted in 'Zi Qiu' leaves.

We investigated the possible basis of differences in growth of B. cinerea in the HR genotype ' $\mathrm{Zi}$ Qiu' compared with HS 'Riesling'. ROS is commonly produced in response to pathogen attack $[25,26]$ and overall, higher levels of ROS accumulated in 'Riesling'. This is not consistent with a study suggesting that in host-pathogen interactions where the pathogen is a necrotroph, pathogen-induced cell death and ROS accumulation promote pathogen growth and disease development. Thus, ROS facilitate colonization on the leaves by the necrotrophic fungus $B$. cinerea [27]. In contrast, low ROS levels were observed here post-inoculation in ' $\mathrm{Zi}$ Qiu', suggesting that the anti-oxidative system maintains redox equilibrium [26,28] and protects cells from ROS damage [29].

Oxidative stress disturbs the redox equilibrium in infected tissues, thereby promoting disease development [30]. In the current study, ROS accumulation after inoculation was detected in leaves from both genotypes, but with higher levels in 'Riesling'. We conclude that 'Riesling' suffered significantly from the continued presence of ROS, and that ' $\mathrm{Zi}$ Qiu' did not experience substantial oxidative stress due to a high and timely anti-oxidative capacity. $\mathrm{H}_{2} \mathrm{O}_{2}$ higher or lower levels increase either the susceptibility or resistance respectively to $B$. cinerea, while, $\mathrm{O}_{2}{ }^{-}$serves as a first substrate for $\mathrm{H}_{2} \mathrm{O}_{2}$ formation $[13,30,31]$. Some reports have suggested that $\mathrm{O}_{2}{ }^{-}$plays a role in supporting $B$. cinerea invasion [32,33]. $\mathrm{H}_{2} \mathrm{O}_{2}$ production is induced in plant cells, accompanied by $\mathrm{O}_{2}{ }^{-}$generation, which can promote programmed cell death and disease lesion development, thereby increasing B. cinerea infection [27]. We propose that the high and low levels of ROS in 'Riesling' and 'Zi Qiu' contribute to their susceptibility and resistance to B. cinerea infection, respectively [34].

We evaluated ROS accumulation and antioxidant enzyme activities during the interactions with B. cinerea [33]. Low ROS production and a timely increase in the activity of anti-oxidative enzymes were associated with the strong pathogen resistance of 'Pingli-5' and the HS cultivar 'Red Globe', which suffers from severe infection and sustained ROS production correlated with comparatively unchanged anti-oxidative activities [11]. These results support the significance of the ROS response in 
a timely detection of and defense against $B$. cinerea. We saw that the post-inoculated 'Riesling' leaves showed a slight variation in POD activity with lesion development. However, they showed increased SOD activity, which corresponded well with $\mathrm{H}_{2} \mathrm{O}_{2}$ production and a reduction in $\mathrm{O}_{2}{ }^{-}$. The POD activity in ' $\mathrm{Zi}$ Qiu' increased during the experiment, and no significant change was observed in SOD activity. Low levels of ROS accumulation are necessary for the anti-oxidative system to sustain redox equilibrium [26], and we also observed that the infected 'Riesling' showed evidence of an insufficient anti-oxidative system, resulting in consistently elevated ROS levels. In contrast, 'Zi Qiu' showed relatively rapid changes in anti-oxidative capacity, especially POD activity, following inoculation, and thus likely experienced less ROS-induced stress. Given that substantial levels of ROS were induced in 'Riesling' but not in 'Zi Qiu', we propose that the coordination between ROS production and scavenging mechanisms associated with the anti-oxidative system during biotic stress [35] may be a key factor in the ability of genotype 'Zi Qiu' to shield itself against B. cinerea.

JA levels were measured in both the HR and HS genotypes, and higher levels found in 'Zi Qiu'. We noted high levels of JA in the 'Zi Qiu' control, which were approximately equal to the JA levels seen in inoculated 'Riesling' (Figure 5), indicating that a continuously high presence of JA in 'Zi Qiu' may contribute to controlling B. cinerea, and possibly other pathogens. These results are consistent with another study [36], which stated that high JA levels block $B$. cinerea infection and strengthen grape resistance to $B$. cinerea. Moreover, JA is known to be a major hormone involved in plant defense responses [37] and is a crucial component in the plant defense responses against insects and microbial pathogens [38]. JA accumulation occurs relatively quickly in plant tissues and cells after exposure to fungal elicitors $[39,40]$. JA is involved in plant response to injury and biotic stresses, such as occurs during insect and pathogen attacks [7,41], and is associated with resistance to biotrophic and necrotrophic pathogens $[16,42]$.

\section{Materials and Methods}

\subsection{Plant and Fungal Materials}

Plant materials were obtained from the Grape Repository $\left(34^{\circ} 12^{\prime} \mathrm{N}, 108^{\circ} 07^{\prime} \mathrm{E}\right)$ of Northwest A \& F University, Yangling, Shaanxi, China. The area is situated $520 \mathrm{~m}$ above sea level. Mean annual temperature and precipitation are $12.9^{\circ} \mathrm{C}$ and $660 \mathrm{~mm}$. Most of the precipitation occurs between July and September. All the grape genotypes were cultivated in the grape germplasm depository at the Northwest A\&F University, Yangling, Shaanxi, China. Fifteen plants per genotype were used for leaf evaluation. Leaves were sampled on the same dates ( \pm 3 days) in the years 2016-2017 i.e., 23 May, (genotypes 1-10), 28 May, (genotypes 11-20), 3 June, (genotypes 21-30), 8 June, (genotypes 31-40), 12 June, (genotypes 41-50), 16 June, (genotypes 51-60), 20 June, (genotypes 61-70), 25 June, (genotypes 71-81). All 81 Vitis genotypes collectively belong to the following grape species: $(V$. vinifera $\times V$. labrusca $),(V$. vinifera $),(V$. vinifera $\mathrm{L}$ $\times V$. amurensis), (V.amurensis), and (V. davidii). Their taxonomic information was retrieved from [43,44], and detailed information for each of the species is available in Table S1. The material was used to evaluate gray mold disease development in 2016 and 2017.

B. cinerea spores were isolated from the seedless cultivar 'Flame' $(V$. vinifera $)$ in a greenhouse located on the North campus of the Northwest A\&F University, Shaanxi, China. Spores were cultured on a potato dextrose agar medium at $22{ }^{\circ} \mathrm{C}$. After 20 days, the conidia were removed, and $1.5 \times 10^{6}$ spores $\mathrm{mL}^{-1}$ were prepared in sterilized water, since this has previously been identified as the optimum inoculum [11]. The conidial suspension was confirmed to have a conidia/spore germination percentage of $95 \%$ or more before all experiments.

\subsection{Detached Leaf Evaluation}

Leaves of the same size and age (from the shoot at nodes 3 and 4) were arbitrarily selected from the grape plants. The detached leaves were washed with distilled water. For laboratory assessment, 24 leaves from each of three replicates of each genotype were evaluated. The leaves were quickly 
transferred to trays with $0.8 \%$ agar and sprayed evenly with the conidial suspension. Control leaves were sprayed with distilled water. The trays were placed in an incubator with a relative humidity of $90-100 \%$, for the first $24 \mathrm{~h}$ in the dark and then $12 / 12 \mathrm{~h}$ light/dark at $22{ }^{\circ} \mathrm{C}$.

\subsection{Disease Severity Rating}

Disease severity was evaluated and rated as previously described $[45,46]$ with slight modifications. The disease symptoms observed on the leaves were ranked from 1 to 7 (Rank $1=0.1-5.0 \%, 2=5.1-15.0 \%$, $3=15.1-30.0 \%, 4=30.1-45.0 \%, 5=45.1-65 \%, 6=65.1-85.0 \%$ and $7=85.1-100.0 \%$ ) on the basis of the estimated percentage of lesion over the entire leaf surface. The ranking was then converted into a severity index (SI) according to the formula:

$$
\mathrm{SI}=\frac{\sum(\text { Rank } \times \text { number of infected leaves in that rank })}{\text { Total number of leaves } \times \text { highest rank }} \times 100
$$

The resistance level was rated into four classes on the basis of the SI values. Disease resistance levels of the different genotypes were categorized as highly resistant (SI: 0-1.50), resistant (SI: 1.51-3.50), susceptible (SI: 3.51-5.50), and highly susceptible (SI: 5.51-7.0). Susceptibility data for the disease were collected in 2016 and 2017. The average SI values of the two-year data were used to evaluate the resistance level.

\subsection{Light Microscopy}

Two representative genotypes from each category were used to characterize the colonization of the grape leaves by $B$. cinerea using light microscopy. The following genotypes were used for each category: HR, 'Zi Qiu' and 'Ju Mei Gui'; R, 'Kang San' and 'Rizamat'; S, 'Flame' and 'Canner'; HS, 'Riesling' and 'Pinot noir'. The leaves were cut into $2-3 \mathrm{~cm}^{2}$ segments and fixed and decolorized in $100 \%$ ethanol and in saturated chloral hydrate. The samples were stored in $50 \%$ glycerol and stained with anilineblue solution at the time of observation with an Olympus BX-51 microscope (Olympus, Tokyo, Japan) [47].

\subsection{SEM}

The development of B. cinerea on leaves of two representative genotypes, 'Zi Qiu' and 'Riesling', was observed using SEM (JEOL FESEM S-4800 scanning electron microscope, JEOL, Tokyo, Japan). Infected leaves were cut into $1.0-1.5 \mathrm{~cm}^{2}$ pieces at various time points $(4,8,12,18,24,36,48,72$, and 96) hpi and immersed in $4 \%$ glutaraldehyde. After vacuum infiltration for $30 \mathrm{~min}$, the infected leaves were rinsed five times for 5, 10, 15, 20, $20 \mathrm{~min}$, respectively, with $0.1 \mathrm{M}$ sodium phosphate buffer (PBS) ( $\mathrm{pH}$ 6.8). The segments were dehydrated in an ethanol gradient: $30 \%, 50 \%$, and $70 \%$ for $15 \mathrm{~min}$ each; $80 \%$ and $90 \%$ for $20 \mathrm{~min}$ each; and $100 \%$ alcohols twice for $30 \mathrm{~min}$. Finally, the samples were incubated in acetone for $30 \mathrm{~min}$ and isoamyl acetate twice for 15 and $30 \mathrm{~min}$ in three biological replicates. The segments were desiccated by $\mathrm{CO}_{2}$, coated with gold in a sputter coater, and then observed under a scanning electron microscope at $15 \mathrm{kV}$ [47].

\subsection{ROS Measurement}

\subsection{1. $\mathrm{H}_{2} \mathrm{O}_{2}$ Measurement}

$\mathrm{H}_{2} \mathrm{O}_{2}$ content in ' $\mathrm{Zi}$ Qiu' and 'Riesling' leaves was determined at different time points $(0,4,8,12$, $18,24,36,48,72$, and $96 \mathrm{hpi}$ ) as previously described [48].

\subsection{2. $\mathrm{O}_{2}{ }^{-}$Measurement}

The ' $\mathrm{Zi}$ Qiu' and 'Riesling' $\mathrm{O}_{2}{ }^{-}$production rates were calculated at different time points $(0,4,8$, $12,18,24,36,48,72$, and $96 \mathrm{hpi}$ ) as previously described [49] 


\subsection{Enzyme Extraction and Activity Assays}

SOD activity was measured in extracts from 'Zi Qiu' and 'Riesling' leaves at different time points $(0,4,8,12,18,24,36,48,72$, and $96 \mathrm{hpi})$ as previously described [28]. Similarly, POD activity was measured at different time points $(0,4,8,12,18,24,36,48,72,96 \mathrm{hpi})$ as previously described [50] using about $0.5 \mathrm{~g}$ leaves with three biological replicates [51].

\subsection{JA Quantification in HR and HS Genotypes}

JA levels were quantified in inoculated and control 'Zi Qiu' and 'Riesling' leaves that were collected at different time points $(0,12,24,48,72$, and $96 \mathrm{hpi})$ and immediately frozen in liquid nitrogen. The samples were ground in liquid nitrogen with help of pestle and mortar and then stirred in $80 \%$ methanol at $4{ }^{\circ} \mathrm{C}$ overnight. The extract was methylated as previously described [52] and JA was quantified with a competitive enzyme-linked immunosorbent assay (ELISA) assay [53].

\subsection{Statistical Analysis}

Experiments were performed using three biological replicates in a randomized design. Means and standard errors were computed from independent replicates using SPSS 13.0 (SPSS Inc., Chicago, IL, USA). Least significant difference (LSD) 0.05 was employed to compute significant differences, and correlation data of the resistance evaluation from 2016 and 2017 were analyzed. All images were processed with Adobe Photoshop (Adobe Systems Incorporated, San Jose, CA, USA). All graphs were prepared using the Origin Pro 2016 32-bit software (Shenzhen, Guangdong, China) and correlation analysis was performed using the Pearson coefficient.

\section{Conclusions}

In this study, we investigated the resistance levels of different Vitis genotypes to B. cinerea. Most genotypes were susceptible, but a detached leaf assay revealed high resistance in clone 'Zi Qiu' ( $V$. davidii) of Vitis germplasm. The results were further investigated by comparing fungal growth, ROS responses, JA levels, and changes in the antioxidant system, between the HS V. vinifera 'Riesling' genotype and the HR $V$. davidii 'Zi Qiu' genotype after B. cinerea inoculation. We observed that low ROS production, rapid elevation in antioxidant activities and high JA levels were associated with a high level of fungal resistance in 'Zi Qiu'. In contrast, the HS genotype 'Riesling' suffered from severe $B$. cinerea infection and sustained ROS production, together with relatively unchanged anti-oxidative activities and low JA levels. This study provides insights into B. cinerea infection of grape leaves, as well as information that may be valuable to breeders in selecting germplasm for increased disease resistance.

Supplementary Materials: The supplementary materials are available online.

Author Contributions: X.W. and M.U.R. designed the experiments. M.U.R. and M.H. conducted the experiments. M.U.R. wrote the manuscript. R.W., X.H. and B.A. helped with the experiments. X.W. critically reviewed the paper.

Funding: This work was supported by The National Key Research and Development Program of China (2018YFD0201300), as well as the National Natural Science Foundation of China (31572110) and the Program for Innovative Research Team of Grape Germplasm Resources and Breeding (2013KCT-25).

Acknowledgments: We thank Jocelyn Rose for editing this manuscript.

Conflicts of Interest: The authors declare no conflict of interest.

\section{Abbreviations}

$\begin{array}{ll}\text { ROS } & \text { reactive oxygen species } \\ \text { HR } & \text { highly resistant } \\ \text { HS } & \text { highly susceptible } \\ \text { SOD } & \text { superoxide dismutase } \\ \text { POD } & \text { peroxidase } \\ \text { JA } & \text { jasmonic acid }\end{array}$




$\begin{array}{ll}\mathrm{H}_{2} \mathrm{O}_{2} & \text { hydrogen peroxide } \\ \mathrm{O}_{2}^{-} & \text {superoxide radicals } \\ \text { SI } & \text { severity index } \\ \mathrm{HPI} & \text { hours post inoculation } \\ \text { SEM } & \text { scanning electron microscope }\end{array}$

\section{References}

1. Dean, R.; Van Kan, J.A.L.; Pretorius, Z.A.; Hammond-Kosack, K.E.; Di Pietro, A.; Spanu, P.D. The top 10 fungal pathogens in molecular plant pathology. Mol. Plant Pathol. 2012, 13, 414-430. [CrossRef] [PubMed]

2. Cadle-davidson, L. Monitoring pathogenesis of natural. Vitis 2008, 4, 387-395.

3. Percival, D.; Fisher, K.; Sullivan, J. Use of fruit zone leaf removal with Vitis vinifera L. cv. Riesling grapevines. II. Effect on fruit composition, yield and occurrence of bunch rot (Botrytis cinerea Pers.: Fr.). Am J. Enol. Vitic. 1994, 45, 133-140.

4. Kulakiotu, E.K.; Thanassoulopoulos, C.C.; Sfakiotakis, E.M. Postharvest biological control of Botrytis cinerea on kiwifruit by volatiles of [Isabella] Grapes. Phytopathology 2004, 94, 1280-1285. [CrossRef] [PubMed]

5. Gessler, C.; Pertot, I.; Perazzolli, M. Plasmoparaviticola: A review of knowledge on downy mildew of grapevine and effective disease management. Phytopathol. Mediterr. 2011, 50, 3-44.

6. Angelini, D.M.R.M.; Masiello, M.; Rotolo, C.; Pollastro, S.; Faretra, F. Molecular characterisation and detection of resistance to succinate dehydrogenase inhibitor fungicides in botryotinia fuckeliana (Botrytis cinerea). Pest Manag. Sci. 2014, 70, 1884-1893. [CrossRef]

7. Savocchia, S.; Stummer, B.E.; Wicks, T.J.; Vanheewijck, R.; Scorr, E.S. Reduced sensitivity of Uncinula necator to sterol demethylation inhibiting fungicides in southern Australian vineyards. Australas. Plant Pathol. 2004, 33, 465-473. [CrossRef]

8. Kretschmer, M.; Leroch, M.; Mosbach, A.; Walker, A.S.; Fillinger, S.; Mernke, D.; Schoonbeek, H.; Pradier, J.M.; Leroux, P.W.; Hahn, M. Fungicide driven evolution and molecular basis of multidrug resistance in field population of grey mould fungus Botrytis cinerea. PLoS Pathog. 2009, 5, e1000696. [CrossRef]

9. LI, H. Studies on the resistance of grapevine to powdery mildew. Plant Pathol. 1993, 42, 792-796. [CrossRef]

10. Peros, J.P.; Nguyen, T.H.; Troulet, C.; Michel-Romitti, C.; Notteghem, J.L. Assessment of powdery mildew resistance of grape and Erysiphe necator pathogenicity using laboratory assay. Vitis 2006, 45, 29-36.

11. Wan, R.; Hou, X.; Wang, X.; Qu, J.; Singer, S.D.; Wang, Y.; Wang, X. Resistance evaluation of Chinese wild Vitis genotypes against Botrytis cinerea and different responses of resistant and susceptible hosts to the infection. Front. Plant Sci. 2015, 6, 1-17. [CrossRef] [PubMed]

12. Liu, Y.; He, C. Regulation of plant reactive oxygen species (ROS) in stress responses: Learning from AtRBOHD. Plant Cell Rep. 2016, 35, 995-1007. [CrossRef]

13. Govrin, E.M.; Levine, A. The hypersensitive response facilitates plant infection by the necrotrophic pathogen Botrytis cinerea. Curr. Biol. 2000, 10, 751-757. [CrossRef]

14. Temme, N.; Tudzynski, P. Does Botrytis cinerea ignore $\mathrm{H}_{2} \mathrm{O}_{2}$-induced oxidative stress during infection? Characterization of botrytis activator protein 1. APS J. 2009, 22, 987-998.

15. Durrant, W.E.; Dong, X. Systemic acquired resistance. Annu. Rev. Phytopathol. 2004, 42, 185-209. [CrossRef] [PubMed]

16. Glazebrook, J. Contrasting mechanisms of defense against biotrophic and necrotrophic pathogens. Annu. Rev. Phytopathol. 2005, 43, 205-227. [CrossRef]

17. Wasternack, C.; Hause, B. Jasmonates: Biosynthesis, perception, signal transduction and action in plant stress response, growth and development. An update to the 2007 review in Annals of Botany. Ann. Bot. 2013, 111, 1021-1058. [CrossRef]

18. Poolsawat, O.; Tharapreuksapong, A.; Wongkaew, S.; Chaowiset, W.; Tantasawat, P. Laboratory and field evaluations of resistance to Sphaceloma ampelinum causing anthracnose in grapevine. Australas. Plant Pathol. 2012, 41, 263-269. [CrossRef]

19. Karuppanapandian, T.; Moon, J.C.; Kim, C.; Manoharan, K.; Kim, W. Reactive oxygen species in plants: Their generation, signal transduction, and scavenging mechanisms. Aust. J. Crop Sci. 2011, 5, 709-725. 
20. Gabler, F.M.; Smilanick, J.L.; Mansour, M.; Ramming, D.W.; Mackey, B.E. Correlations of morphological, anatomical, and chemical features of grape berries with resistance to Botrytis cinerea. Phytopathology 2003, 93, 1263-1273. [CrossRef]

21. Liu, L.; Li, H. Review: Research progress in amur grape, Vitis amurensis Rupr. Can. J. Plant Sci. 2013, 93, 565-575. [CrossRef]

22. Wang, Y.; Liu, Y.; He, P.; Chen, J.; Lamikanra, O.; Lu, J. Evaluation of foliar resistance to Uncinula necator in Chinese wild Vitis spp. species. Vitis 1995, 34, 159-164.

23. Wang, Y.; Liu, Y.; He, P.; Lamikanra, O.; Lu, J. Resistance of Chinese Vitis species to Elsinoe ampelina (de Bary) Shear. HortScience 1998, 33, 123-126.

24. Liu, R.; Wang, L.; Zhu, J.; Chen, T.; Wang, Y.; Xu, Y. Histological responses to downy mildew in resistant and susceptible grapevines. Protoplasma 2014, 252, 259-270. [CrossRef] [PubMed]

25. Torres, M.A.; Jones, J.D.G.; Dangl, J.L. Reactive oxygen species signaling in response to pathogens. Plant Physiol. 2006, 141, 373-378. [CrossRef] [PubMed]

26. Foyer, C.H.; Noctor, G. Redox signaling in plants. Antioxid. Redox Signal. 2013, 18, 2087-2090. [CrossRef] [PubMed]

27. Asai, S.; Yoshioka, H. Nitric oxide as a partner of reactive oxygen species participates in disease resistance to necrotrophic pathogen Botrytis cinerea in nicotiana benthamiana. APS J. 2009, 22, 619-629. [CrossRef]

28. Mittler, R.; Vanderauwera, S.; Suzuki, N.; Miller, G.; Tognetti, V.B.; Vandepoele, K. ROS signaling: The new wave? Trends Plant Sci. 2011, 16, 300-309. [CrossRef]

29. Sharma, P.; Jha, A.B.; Dubey, R.S.; Pessarakli, M. Reactive oxygen species, oxidative damage, and antioxidative defense mechanism in plants under stressful conditions. J. Bot. 2012, 2012, 1-26. [CrossRef]

30. Smilanick, J.L.; Mansour, M.F.; Gabler, F.M.; Margosan, D.A.; Hashim-Buckey, J. Control of post-harvest gray mold of table grapes in the San Joaquin Valley of California by fungicides applied during the growing season. Plant Dis. 2010, 94, 250-257. [CrossRef]

31. Asselbergh, B.; Curvers, K.; Franca, S.C.; Audenaert, K.; Vuylsteke, M.; Van Breusegem, F. Resistance to Botrytis cinerea in sitiens, an abscisic acid-deficient tomato mutant, involves timely production of hydrogen peroxide and cell wall modifications in the epidermis. Plant Physiol. 2007, 144, 1863-1877. [CrossRef] [PubMed]

32. Patykowski, J. Role of hydrogen peroxide and apoplastic peroxidase in tomato-Botrytis cinerea interaction. Acta Physiol. Plant. 2006, 28, 589-598. [CrossRef]

33. Zhang, Y.; Liu, B.; Li, X.; Ouyang, Z.; Huang, L.; Hong, Y. The denovo biosynthesis of vitamin B6 is required for disease resistance against Botrytis cinerea in tomato. Mol. Plant-Microbe Interact. 2014, 27, 688-699.

34. Simon, U.K.; Polanschütz, L.M.; Koffler, B.E.; Zechmann, B. High resolution imaging of temporal and spatial changes of subcellular ascorbate, glutathione and $\mathrm{H}_{2} \mathrm{O}_{2}$ distribution during Botrytis cinerea infection in Arabidopsis. PLoS ONE 2013, 8, e65811. [CrossRef]

35. Atkinson, N.J.; Urwin, P.E. In Posidonia oceanica cadmium induces changes in DNA methylation and chromatin patterning. J. Exp. Bot. 2012, 63, 695-709.

36. Jia, H.; Zhang, C.; Pervaiz, T.; Zhao, P.; Liu, Z.; Wang, B. Jasmonic acid involves in grape fruit ripening and resistant against Botrytis cinerea. Funct. Integr. Genom. 2016, 16, 79-94. [CrossRef]

37. Bruinsma, M.; Van Dam, N.M.; Van Loon, J.J.A.; Dicke, M. Jasmonic acid-induced changes in brassica oleracea affect oviposition preference of two specialist herbivores. J. Chem. Ecol. 2007, 33, 655-668. [CrossRef] [PubMed]

38. Bari, R.; Jones, J.D.G. Role of plant hormones in plant defence responses. Plant Mol. Biol. 2009, 69, 473-488. [CrossRef]

39. Li, C.; Schilmiller, A.L.; Liu, G.; Lee, G.I.; Jayanty, S.; Sageman, C. Role of beta-oxidation in jasmonate biosynthesis and systemic wound signaling in tomato. Plant Cell. 2005, 17, 971-986. [CrossRef]

40. Kang, J.H.; Wang, L.; Giri, A.; Baldwin, I.T. Silencing threonine deaminase and JAR4 in nicotiana attenuata impairs jasmonic acid-isoleucine-mediated defenses against manduca sexta. Plant Cell. 2006, 18, 3303-3320. [CrossRef]

41. Shan, X.; Zhang, Y.; Peng, W.; Wang, Z.; Xie, D. Molecular mechanism for jasmonate-induction of anthocyanin accumulation in arabidopsis. J. Exp. Bot. 2009, 60, 3849-3860. [CrossRef] [PubMed]

42. Robert-Seilaniantz, A.; Navarro, L.; Bari, R.; Jones, J.D. Pathological hormone imbalances. Curr. Opin. Plant Biol. 2007, 10, 372-379. [CrossRef] [PubMed] 
43. Wu, X.; Liu, N.; Zhang, J.; Wang, Y. Field natural identification of resistance of grape resources from USA and Xinjiang of China to primary fungi diseases. J. Frui. Sci. 2011, 28, 849-856.

44. Liu, C.; Ma, X.; Wu, G. Grape Varieties in China; Chinese Agriculture Press: Beijing, China, 2014.

45. Li, D.; Wan, Y.; Wang, Y.; He, P. Relatedness of resistance to anthracnose and to white rot in Chinese wild grapes. Vit. J. Grapevine Res. 2008, 47, 213-215.

46. Liu, S.M.; Sykes, S.R.; Clingeleffer, P.R. A method using leafed single-node cuttings to evaluate downy mildew resistance in grapevine. Vitis 2003, 42, 173-180.

47. Cheng, Y.; Zhang, H.; Yao, J.; Wang, X.; Xu, J.; Han, Q. Characterization of non-host resistance in broad bean to the wheat stripe rust pathogen. BMC Plant Biol. 2012, 12, 96. [CrossRef]

48. Moloi, M.J.; Westhuizen, A.J. The reactive oxygen species are involved in resistance responses of wheat to the Russian wheat aphid. J. Plant Physiol. 2006, 163, 1118-1125. [CrossRef]

49. Elstner, E.F.; Heupel, A. Formation of hydrogen peroxide by isolated cell walls from horseradish (Armoracia lapathifolia Gilib). Planta 1976, 320, 317-320. [CrossRef]

50. Maehly, A.C.; Chance, B. Theassayofcatalases andperoxidases. Meth. Biochem. Anal. 1954, 1, 357-424.

51. Giannopolitis, C.N.; Ries, S.K. Superoxide dismutases. Biol. Roles Copp. 1977, 125-142.

52. Royo, J.; Leon, J.; Vancanneyt, G.; Albar, J.P.; Rosahl, S.; Ortego, F. Antisense-mediated depletion of a potato lipoxygenase reduces wound induction of proteinase inhibitors and increases weight gain of insect pests. Proc. Natl. Acad. Sci. USA 1999, 96, 1146-1151. [CrossRef] [PubMed]

53. Albrecht, T.; Kehlen, A.; Stahl, K.; Knöfel, H.D.; Sembdner, G.; Weiler, E.W. Quantification of rapid, transient increases in jasmonic acid in wounded plants using a monoclonal antibody. Planta 1993, 191, 86-94. [CrossRef]

Sample Availability: Not Available.

(C) 2018 by the authors. Licensee MDPI, Basel, Switzerland. This article is an open access article distributed under the terms and conditions of the Creative Commons Attribution (CC BY) license (http:/ / creativecommons.org/licenses/by/4.0/). 